\title{
Developmental Characteristics of Spelling Ability according to the Types of Linguistic Units (Word/ Sentence) for Lower Grade Elementary School Children
}

\author{
Eun Yi Ko ${ }^{a}$, Myungsun Shin ${ }^{b}$, Mibae Kim ${ }^{c}$ \\ ${ }^{a}$ Igonggam Child Mental Health Clinic, Busan, Korea \\ ${ }^{b}$ Department of Speech and Hearing Therapy, Catholic University of Pusan, Busan, Korea \\ ${ }^{c}$ Daon Language Learning Center, Seongnam, Korea
}

\author{
Correspondence: Myungsun Shin, PhD \\ Department of Speech, Hearing and Language \\ Thearpy, Catholic University of Pusan, 57 \\ Oryundae-ro, Geumjeong-gu, Busan 46252, Korea \\ Tel: $+82-51-510-0842$ \\ Fax: +82-51-510-0848 \\ E-mail: sms2012@hanmail.net
}

Received: April 5, 2020

Revised: April 28, 2020

Accepted: May 4, 2020

This work is based on the master's thesis of the first author

\begin{abstract}
Objectives: The purpose of this study was to examine the accuracy of spelling and types of errors through grade-level word and sentence dictation tasks for general children in lower grade elementary school (grades 1-3). Methods: The subjects of this study were 60 TD children in grades 1 to 3 (20 students in each grade) from elementary schools. The spelling test was constructed to include words implemented in word-level tasks at the sentence level based on textbooks revised in 2017 and 2018 that were being used in grades 1 to 3 used in actual school sites. Results: First, The spelling accuracy at the word level was significantly lower than the whole word segment accuracy at the sentence level. There was no significant difference between task types in the accuracy at the word level and the target word for the sentence level. Second, All grades showed orthographic errors, morphological errors, and phonological errors. When analyzed according to task types, the error level was similar at the word and sentence level in the order of orthographic errors, morphological errors, and phonological errors. Conclusion: Spelling ability is active in the lower grade of elementary school, confirming that it is an important ability to develop during this period. Therefore, if writing grade characteristics are considered in the evaluation and setting of intervention goals for children who have difficulty spelling, this suggests that a positive writing instruction is achieved.
\end{abstract}

Keywords: School aged-children, Lower grade elementary school children, Spelling ability, Writing development, Spelling errors
언어 능력은 학령전기까지 구어를 중심으로 발달하고, 학령기가 되면서 읽기·쓰기와 같은 문해 능력의 발달과 통합된다. 쓰기는 읽 기와 함께 학령기 아동에게 중요한 문해 능력이다. 학령기에는 보 다 높은 수준의 언어를 습득하여 문해 기술을 통해 새로운 지식을 학습한다. 또한 학령기에는 상위언어능력을 기반으로 읽기 및 쓰기 능력이 발달하는 시기로(Van Kleeck, 1994; Vellutino, Fletcher, Snowling, \& Scalon, 2004), 읽기와 상위언어능력을 함께 살펴보는 연구들이 활발하게 이루어지고 있다(Aan \& Lee 2019; Han \& Kim,
2018). 이러한 연구들에서는 음운 인식, 형태 인식과 같은 상위언어 능력을 활용하여 읽기가 이루어진다고 보고되었다. 읽기 시에는 단 어를 보고 구성하는 자소들을 분석한 후, 조합하는 과정을 거치지 만 쓰기 시에는 단어를 떠올리고 음소를 분석한 후, 표기하는 소리 를 선택하여 조합하는 과정을 거친다(Kim, Lee \& Yang, 2018). 따 라서 쓰기 역시 상위언어능력을 기반으로 학령기에 발달한다고 할 수 있다.

학령기 아동 중 쓰기에 어려움이 있는 아동은 $4 \%$ 이상이라고 보 
고되었다(Kim, Choi \& Kim, 2010). 하지만 2013년도 교육부에서 실시한 '기초학습 진단평가'에서 읽기 미도달 아동은 $4.55 \%$ 인 반면 쓰기 미도달 아동은 $10.51 \%$ 로(Kim, 2016) 최근 쓰기에 어려움이 있는 아동들이 급격하게 증가하는 추세이다. 다양한 대상으로 살 펴본 연구에서 언어학습장애, 난독증, 말소리 장애가 일반 아동들 에 비해 철자 능력에 어려움이 있는 것으로 나타났다(Han \& Jung, 2018; Kim, 2016; McNeill, Wolter \& Gillon, 2017; Yang, Kim \& Ra, 2017).

쓰기는 대부분 철자 쓰기와 작문으로 나눌 수 있다. 철자 쓰기는 정확히 받아쓰는 것이며 작문은 글로 자신의 생각과 감정을 표현 하는 것이다. 최근 다양한 스마트 기기가 활발하게 사용됨으로써 SNS (Social Network Service)를 통해 자신의 생각이나 느낌을 문 자로 의사소통하는 기회가 많아지고 있다(Baek, 2009; Ye, Kim \& Rhee, 2017). 따라서 쓰기의 어려움은 학업 부진과 의사소통 및 사 회적 행동 문제로 이어질 수 있으며(Berninger et al., 2006), 진로 결 정과 사회 - 경제적인 기회 획득에도 영향을 미치게 된다(Katusic,

Colligan, Weaver, \& Barbaresi, 2009).

단순 쓰기 모델(simple view of writing)에 따르면 쓰기 능력은 철 자 쓰기, 글자 쓰기, 작문으로 구성된다(Berninger, Cartwright, Yates, Swanson \& Abbott, 1994). 그 중에서 쓰기의 궁극적인 목표인 작문 을 성공하기 위해서 철자 쓰기는 반드시 선행되어야 하는 조건이 다. 언어적 지식과 음운인식, 철자 표기 인식, 형태 인식 등의 상위언 어능력으로 쓰기 능력을 예측할 수 있다(Apel \& Masterson, 2001; Berninger et al., 2006). 음운 산출과 언어 이해 발달이 결합이 되었 을 때 자동적인 철자 쓰기가 가능해지므로 언어적인 요소들이 철 자 쓰기에 영향을 미친다고 할 수 있다. 또한, 형태 인식이 쓰기를 예측하는 변인이라고 하였으며(Han \& Kim, 2018), 철자 쓰기가 이 루어질 때 음운 지식만이 아니라 다양한 언어적인 능력이 필요하기 때문에 형태 인식과 같은 상위언어능력의 습득이 필요하다고 하였 다(Berninger et al., 2006). 따라서 최근 연구들에서 이러한 상위언 어능력의 형태 인식이 읽기와 쓰기를 예측하는 요인이라고 하였다 (Han \& Kim, 2018; Jung, 2019).

Henderson과 Templetion (1986)은 철자 발달을 음운 처리 단계, 패턴 처리 단계, 형태 처리 단계로 제시하였다. 음운 처리 단계에는 단어의 소리와 낱자 또는 글자를 연결짓고, 패턴 처리 단계에는 아 동이 단어의 자소-음소 불일치가 있음을 인식하고 낱자군 또는 패 턴과 소리를 연결한다. 마지막으로 형태 처리 단계에는 의미를 지닌 단어는 소리가 바뀌더라도 철자는 변하지 않는다는 형태소 지식을 활용하여 단어 철자에 적용한다. 이러한 철자 발달 이론에 근거한 연구들을 살펴보면 만 5 세에 유아들은 음운 전략이나 패턴 전략을
철자에 사용하지만(Yang, 2009), 자소-음소 불일치형에 대해서는 어려움을 보이며 이후 초등 저학년이 되어서도 마지막 단계인 형태 전략 사용에 어려움이 있다고 하였다(Han \& Jung, 2018). 또한, 대 부분 1학년 때 대부분의 음운 유형이 완성되나 어려운 음운 유형은 3 학년이 되어서야 완성되며 형태 유형은 3학년이 되어서도 완전한 습득이 이루어지지 않는다고 하였다(Yang, 2014). 따라서 철자 발 달이 민감하게 이루어지는 시기인 초등 저학년을 대상으로 학년에 따른 철자 쓰기 발달을 살펴볼 필요가 있다.

철자 쓰기 능력을 알아보기 위한 과제로 작문과 문장 완성하기, 받아쓰기를 통해 많은 연구들이 이루어져 왔다. 작문은 쓰기의 최 종적인 목표로 성공적인 작문을 위해서는 문장의 총 수, 문장 당 절 의 수, 철자 정확률, 쓰기 유창성, 쉼, 어휘 선택 등이 중요하다(Kim, Gatlin, Al Otaiba \& Wanzek, 2018; Koutsoftas, 2016; Sumner, Connelly \& Barnett, 2016). 또한, 문장 완성하기 과제를 통해 맞춤법, 형 태론적, 통사론적으로 쓰기 능력을 살펴볼 수 있으며(Bae, 2015; $\mathrm{Bae}, 2016)$, 더불어 다양한 이야기글, 설명글, 일기 등과 같이 덩이글 형태로 확장하여 작문 성취도, 철자 발달 및 특성, 쓰기 발달에 미치 는 요인을 살펴보았다(Ko, 2007; Lee, Lee \& Kim, 2018; Yoo, 2008).

받아쓰기는 해당 학년의 국어 교과서에서 단어 목록을 만들어 사용할 수 있다는 연구(Moats, 1994)를 바탕으로 대부분의 철자 쓰기 연구에서는 Kim (2003)의 등급별 국어 교육형 어휘를 활용해 왔다(Han \& Jung, 2018; Jung, 2019; Kim \& Yang, 2015; Kim, 2016). 그러나 2017년에 1, 2학년 교과 과정이, 2018년에 3, 4학년 교과 과 정이 수정되어 이를 반영한 어휘 목록으로 살펴볼 필요가 있다.

선행 연구에서 문장 수준의 과제를 제공한 연구들(Byun, 2005; Park \& Chung, 2008; Seo, 2006)이 있으나 과제 구성 시 괄호 채우 기로 제공하거나 어휘 선정 시 교과 과정을 반영하지 않아 제한점 이 있었다. 또한 대부분 단어 수준에서 철자 능력을 살펴보았다 (Han \& Jung 2018; Yang, 2009; Yang et al., 2017). 문장 발달이 이루 어지는 과정에서 단어가 문법형태소와 결합되면서 활용 어미가 변 화되고, 다양한 음운 규칙이 일어나게 되므로 형태 인식과 같은 상 위언어능력을 바탕으로 이루어지는 문장 수준의 철자 쓰기 능력을 살펴야 한다. 문장 받아쓰기 과제는 단어 받아쓰기 과제와 더불어 철자 문제를 평가하는 데 유용한 정보를 포함한다(Tops, Callens, Bijn \& Brysbaert, 2012). 그리고 실제 교육 현장에서도 초등학교 저 학년 아동들에게 문장 수준의 받아쓰기 급수표를 제공하여 실시 하고 있다. 따라서 쓰기의 최종적인 목표인 작문 단계로 나아가기 위해서는 내용에 초점을 두는 단어 수준뿐만 아니라 내용과 함께 문법형태소와 같은 형식을 갖추어 철자 쓰기가 이루어지는 문장 수준도 함께 살펴야한다. 특히 문장 수준의 쓰기에서 다양한 조사, 
어미와같은 문법형태소를 사용하면서 자소-음소 불일치형이 두드 러지게 나타나고 형태 인식과 같은 상위언어능력을 바탕으로 철자 쓰기가 이루어지는 문장 수준에서 철자 쓰기 특성을 반드시 고려 해야한다.

따라서 본 연구에서 초등 저학년(1-3학년) 일반 아동을 대상으 로 학년 별 단어와 문장 수준의 받아쓰기 과제를 통해 철자 쓰기 정확률 및 오류 유형에 따른 철자 쓰기 특성을 살펴보고자 한다. 본 연구는 초등 저학년의 철자 쓰기 발달 특성을 제시함으로써 임상 현장에서 언어학습장애, 쓰기 부진, 난독증 등과 같이 철자 쓰기에 어려움이 있는 아동들의 중재 방향을 제시하는 기초 자료로 활용 할 수 있을 것이다.

연구 문제는 다음과 같다.

1. 학년(1, 2,3학년)과 언어학적 단위(단어, 문장)에 따라 철자 쓰 기 능력에 차이가 있는가?

1) 학년(1,2,3학년)과 언어학적 단위(단어 수준, 문장 수준: 전 체 어절)에 따른 철자 쓰기 능력은 차이가 있는가?

2) 학년(1, 2,3학년)과 언어학적 단위(단어 수준, 문장 수준: 목 표 단어)에 따른 철자 쓰기 능력은 차이가 있는가?

2. 학년(1,2,3학년)에 따라 언어학적 단위(단어, 문장) 별 철자 쓰 기 오류 특성은 어떠한가?

1) 학년(1,2,3학년)에 따라 단어 수준에서 철자 쓰기 오류 특 성은 어떠한가?

2) 학년(1,2,3학년)에 따라 문장 수준에서 철자 쓰기 오류 특 성은 어떠한가?

\section{연구방법}

\section{연구대상}

본 연구는 부산광역시 소재의 초등학교에 재학중인 1-3학년(각 학년별 20명) 일반 아동 총 60 명을 대상으로 하였다. 대상 아동은 한국 비언어 지능검사(K-CTONI-2; Park, 2014)의 도형척도 지능 지수가 80 이상으로 정상 범위에 있으며, 한국어 읽기검사(KOLRA; Pae, Kim, Yoon, \& Jang, 2015)의 언어 · 읽기지수 2의 표준점수 가 90 초과, 받아쓰기에서 백분위수 $25 \%$ ile 초과, 수용-표현어휘력 검사(REVT; Kim, Hong, Kim, Jang, \& Lee, 2009)의 수용어휘력 결 과 정상 범주에 해당하는 아동, 부모나 교사에 의해 신체, 정서, 청 력에 문제가 없다고 보고된 아동으로 선정하였다. 대상자에 대한 간단한 정보는 Table 1 과 같다. 본 연구는 부산가톨릭대학교 기관 생명윤리위원회(Institute Review Board, IRB)의 승인을 받았다(승 인번호: CUPIRB-2019-026).
Table 1. Participants' characteristics

\begin{tabular}{lccc}
\hline & 1st grade ( $\mathrm{N}=20)$ & 2nd grade $(\mathrm{N}=20)$ & 3rd grade $(\mathrm{N}=20)$ \\
\hline Age $(\mathrm{mo})$ & $86.84(3.43)$ & $97.68(4.19)$ & $109.73(3.22)$ \\
Gender (N) & & & \\
Male & 11 & 5 & 9 \\
Female & 9 & 15 & 11 \\
K-CTONI-2 (IO) & $108.26(11.09)$ & $102.89(12.40)$ & $106.16(10.72)$ \\
REVT (raw score) & $90.47(17.99)$ & $91.76(15.86)$ & $107.61(13.49)$ \\
KOLRA (LRO) & $110.57(8.32)$ & $101.70(9.24)$ & $105.33(7.85)$
\end{tabular}

Values are presented as mean (SD).

$\mathrm{mo}=$ months; $\mathrm{K}$-CTONI-2 = Korean Comprehensive Test of Nonverbal Intelligence-2 (Park, 2014); IQ = intelligence quotient; REVT = Receptive \& expressive vocabulary test (Kim, Hong, Kim, Jang, \& Lee, 2009); KOLRA= Korean Language based Reading Assessment (Pae, Kim, Yoon, \& Jahng, 2015); LRO= language reading quotient.

\section{연구도구}

본 연구에서 사용된 철자 쓰기 검사 도구는 언어학적 단위에 따 라 단어 수준과 문장 수준 과제로 나누었고, 단어 수준 과제에서 실 시한 낱말을 문장 수준에서 포함하여 철자 쓰기 검사 도구를 구성 하였다. 단어 수준 과제와 문장 수준 과제는 Appendix 1에 제시하 였다. 또한, 2017년 개정 1-2학년 교과서, 2018년 개정 3-4학년 교과 서를 기반으로 제작하였으며, 실제 학교 현장에서 사용되고 있는 1-3학년 받아쓰기 급수표를 참조하여 구성하였다.

단어 수준 과제는 자소-음소 일치형 4 문항, 자소-음소 불일치형 20 문항, 총 24 문항으로 구성하였다. 자소-음소 불일치형은 초등 저 학년, 중학년에 고빈도로 출현하는 음운 규칙 별로 종성 규칙 4 문 항, 연음화 4 문항, 경음화 4 문항, 기식음화 4 문항, 구개음화 4 문항으 로 구성하였다. 문장 수준 과제는 받아쓰기 급수표를 참조하여 어 절 수를 고려하였고, 단어 수준에서 살펴본 24 개 낱말이 포함된 문 장으로 2 어절 4 문항, 3 어절 4 문항, 4 어절 4 문항, 5 어절 4 문항, 총 24 문항으로 구성하였다.

본 연구자가 구성한 철자 쓰기 검사 도구는 학령기 전문가의 자 문 분석을 통해 지역적 특성이나 보편적으로 허용 가능한 단어를 1 차 수정·보완하였다. 1 차 수정한 철자 쓰기 검사를 낱말의 적절성 과 과제 별 난이도의 적절성을 검증하기 위해 1 급 언어재활사 자격 증을 소지하고, 언어치료 전공 박사 학위를 소지하였으며 임상현상 에서 임상경력이 5년 이상인 아동 언어발달 전문가 5 명에게 내용타 당도를 실시하였다. Likert 5점 척도에 대한 타당도는 단어 수준 타당 도 4.86점, 문장 수준 타당도 4.78점, 전체 구성 타당도 4.58점으로 전 문가 내용타당도를 통해 최종 철자 쓰기 검사도구를 완성하였다.

\section{연구절차}

검사는 언어치료실이나 학교 교실 등과 같은 소음이 적은 조용 
한 장소에서 아동과 검사자가 1:1로 검사를 실시하였다. 선별 검사 (KOLRA, REVT-R, K-CTONI-2)를 실시하여 대상 아동이 본 연구 에 적합한지 확인 후, 실험 도구인 철자 쓰기 검사를 실시하였다. 철 자 쓰기 검사는 검사자가 아동에게 문항을 들려주고 아동이 받아 적도록 하였다. 검사 실시 전 아동에게 과제 실시 방법을 충분히 안 내하고, 문항을 1 회 재요구할 수 있다고 설명하였다. 문항을 다시 들려줄 때에는 처음 제공된 형태의 단어 및 문장 전체를 들려주었 다. 교차균형화(cross-balancing)를 위해 모든 대상 아동에게 단어 수준과 문장 수준 받아쓰기 과제의 순서를 무작위로 실시하였다. 각각의 검사가 끝날 때마다 아동에게 짧은 휴식 시간을 제공하고, 하루에 검사 수행이 어려울 경우 2 회에 나누어 실시하되, 검사 간 간격을 일주일을 넘기지 않도록 하였다.

\section{자료분석}

단어 수준 과제는 정확하게 받아쓴 문항 1 점, 그렇지 못한 문항 0 점, 총 24 점을 만점으로 채점한 후 정확률(정반응한 문항 수/총 문항 수 $\times 100)$ 을 산출하였다. 문장 수준 과제는 두 가지 분석 기준으로 정확률을 분석하였다. 첫째, 어절 단위로 점수화하여 정확하게 받아 쓴 어절은 1 점, 그렇지 못한 어절은 0 점으로 총 84 점을 만점으로 정 확률(정반응한 어절 수/총 어절 수 $\times 100)$ 을 산출하였다. 예를 들어, '느낌을을 모두 정확하게 적은 경우 1점으로 채점하였다. 둘째, 문장 내 단어 수준에서 사용한 목표 단어만을 기준으로 정확하게 받아쓴 문항은 1 점, 그렇지 못한 문항은 0 점으로 총 24 점을 만점으로 정확 률(정반응한 목표 단어 수/총 목표 단어 수 $\times 100)$ 을 산출하였다. 예 를 들어, ‘느낌을 중 ‘느낌’만 정반응한 경우 1점으로 채점하였다.

오류 유형은 단어 수준 과제와 문장 수준으로 나누어 분석하였 다. 단어 수준의 과제에서 오류 유형을 모두 낱말 단위로 채점하여 오류율로 분석하였고, 문장 수준의 과제에서 오류 유형은 문법적 인 요소를 제외한 목표 단어에서 낱말 단위로 오류율을 확인하였 다. 또한, 두 가지 이상 오류가 함께 나타날 경우 중복 체크하여 채 점하였다. 오류 유형은 Han과 Jung (2018)의 오류 유형을 참조하여 음운 처리 오류, 표기 처리 오류, 형태 처리 오류로 나누어 분석하였

Table 2. Spelling ability according to the types of subgroup and tasks (\%)

\begin{tabular}{lcccc}
\hline Unit & $\begin{array}{c}\text { 1st grade } \\
(\mathrm{N}=20)\end{array}$ & $\begin{array}{c}\text { 2nd grade } \\
(\mathrm{N}=20)\end{array}$ & $\begin{array}{c}\text { 3rd grade } \\
(\mathrm{N}=20)\end{array}$ & $\begin{array}{c}\text { Total } \\
(\mathrm{N}=60)\end{array}$ \\
\hline Word level & $62.29(10.85)$ & $74.58(10.28)$ & $82.19(7.51)$ & $73.26(12.77)$ \\
$\begin{array}{l}\text { Sentence level (whole } \\
\text { word segment) }\end{array}$ & $73.27(9.94)$ & $85.65(6.59)$ & $90.23(4.73)$ & $83.05(10.26)$ \\
Total & $67.78(10.42)$ & $80.12(8.44)$ & $86.58(6.12)$ & $78.16(11.51)$ \\
\hline
\end{tabular}

Values are presented as mean (SD).
다. 각각의 오류 유형과 예시는 Appendix 2에 제시하였다.

본 연구에서 사용한 단어 수준 과제, 문장 수준 과제에 대한 신 뢰도를 전체 자료의 $10 \%$ 를 무작위로 선정한 후 평가자 간 신뢰도 를 산출하였다. 신뢰도를 검증하기 위해 1 급 언어재활사 자격증을 소지하고, 언어치료 전공 석사 이상의 학위를 소지하였으며, 임상 현상에서 임상경력이 5 년 이상인 아동 언어발달 전문가 2 명에게 오 류 유형 별 평가자 간 신뢰도를 측정하였다. 그 결과, 단어 수준 및 문장 수준의 신뢰도는 각각 $100 \%$ 로 나타났으며 오류 유형 별 평가 자간 신뢰도는 $94.24 \%$ 로 나타났다.

\section{통계처리}

첫째, 학년(1,2,3학년)과 언어학적 단위(단어, 문장)에 따라 철자 쓰기 능력에 차이가 있는지 알아보기 위해 반복측정 이원분산분 석(two-way ANOVA with repeated measure)을 실시하였다. 둘째, 학년(1, 2, 3학년)에 따라 언어학적 단위(단어, 문장)별 오류 유형 특 성을 알아보기 위해 기술통계를 실시하였다. 통계처리는 SPSS Statistics version 21 프로그램을 이용하여 분석하였다.

\section{연구결과}

\section{학년(1, 2, 3학년)과 언어학적 단위(단어, 문장)에 따른 철자} 쓰기 능력 차이

과제 유형(단어, 문장 수준: 전체 어절)에 따른 학년 별 철자 쓰기능력

본 연구에서 살펴본 학년과 과제 유형에 따른 기술통계 결과는 다음과 같다(Table 2, Figure 1).

학년과 과제 유형에 따른 철자 쓰기 능력에 차이가 있는지를 알 아보기 위해 반복측정 이원분산분석을 실시한 결과는 Table 3과 같다. 철자 쓰기 과제 유형에 따른 학년 간 차이를 살펴본 결과, 학

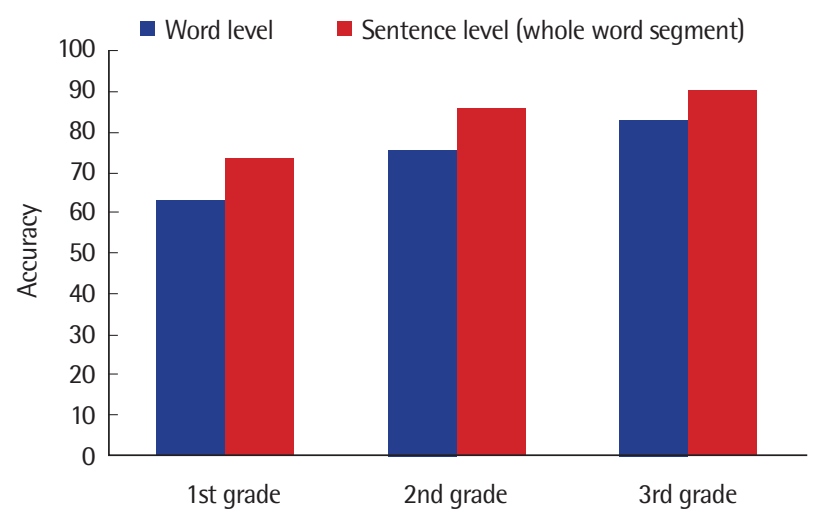

Figure 1. Spelling ability according to the types of subgroup and tasks (\%). 
Eun Yi Ko, et al. • Developmental Characteristics of Spelling Ability

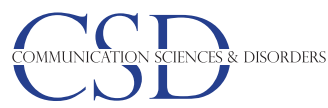

Table 3. Result of two-way ANOVA with repeated measure on spelling accuracy of grade and task type

\begin{tabular}{|c|c|c|c|c|c|}
\hline Source & Sum of squares & df & Mean square & $F$ & Scheffé \\
\hline \multicolumn{6}{|l|}{ Between group } \\
\hline Group & 7,295.109 & 2 & 3647.555 & $28.741^{* * *}$ & $1<2<3$ \\
\hline Error & 7,234.047 & 57 & 126.913 & & \\
\hline \multicolumn{6}{|l|}{ Within group } \\
\hline Task type & 2,876.302 & 1 & 2876.302 & $134.203^{* * *}$ & Word $<$ sentence \\
\hline Task type ×Group & 91.571 & 2 & 45.786 & 2.136 & \\
\hline Error & $1,221.646$ & 57 & 21.432 & & \\
\hline
\end{tabular}

$1=1$ st grade; $2=2$ nd grade; $3=3$ rd grade

${ }^{* * *} p<.001$.

Table 4. Spelling ability according to the types of subgroup and tasks (\%)

\begin{tabular}{lcccc}
\hline Unit & $\begin{array}{c}\text { 1st grade } \\
(\mathrm{N}=20)\end{array}$ & $\begin{array}{c}\text { 2nd grade } \\
(\mathrm{N}=20)\end{array}$ & $\begin{array}{c}\text { 3rd grade } \\
(\mathrm{N}=20)\end{array}$ & Total $(\mathrm{N}=60)$ \\
\hline Word level & $62.29(10.85)$ & $74.58(10.28)$ & $82.19(7.51)$ & $73.26(12.77)$ \\
$\begin{array}{c}\text { Sentence level } \\
\text { (target word) }\end{array}$ & $62.70(13.34)$ & $74.00(10.02)$ & $81.87(9.58)$ & $73.19(13.53)$ \\
$\begin{array}{c}\text { Total } \\
\text { The }\end{array}$ & $62.50(12.10)$ & $74.79(10.15)$ & $82.39(8.54)$ & $73.22(13.15)$
\end{tabular}

Values are presented as mean (SD).

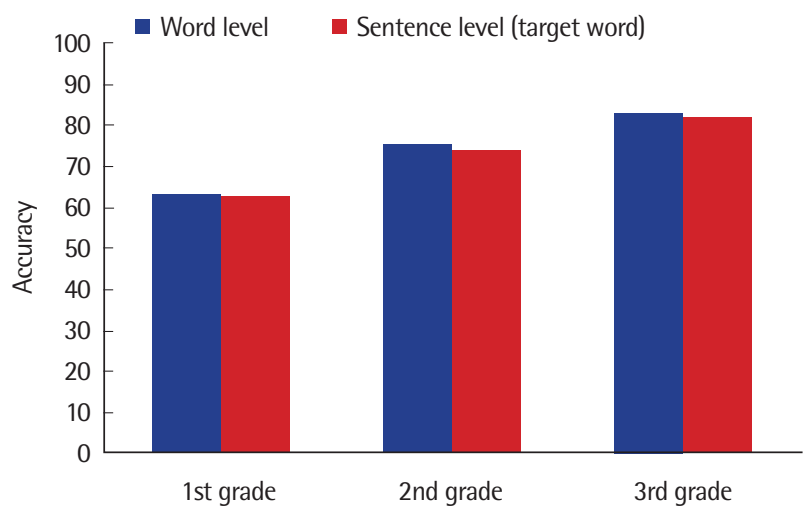

Figure 2. Spelling ability according to the types of subgroup and tasks (\%).

년 간 $F_{(2,57)}=28.741(p<.001)$ 로 유의미한 차이가 나타났고, 사후 분석 결과, 1 학년이 2,3 학년보다, 2 학년이 3 학년보다 철자 쓰기 정 확률이 유의미하게 낮은 것으로 나타났다. 또한, 학년 내 과제 유형 차이를 살펴본 결과, $F_{(1,57)}=134.203$ ( $\left.p<.001\right)$ 으로 문장 수준에서 전체 어절이 단어 수준에 비해 정확률이 유의미하게 높은 것으로 나타났다. 학년과 과제 유형 간 상호작용 효과를 살펴본 결과, $F_{(2,57)}=$ 2.136 ( $p>$.05)으로 상호작용 효과가 없는 것으로 나타났다.

과제 유형(단어, 문장 수준: 목표 단어)에 따른 목표 단어 철자 쓰기 능력의 차이

본 연구에서 살펴본 학년과 과제 유형에 따른 기술 통계 결과는
Table 5. Result of two-way ANOVA with repeated measure on spelling accuracy of grade and task type

\begin{tabular}{lrrrrr}
\hline Source & Sum of squares & df & Mean square & $F$ & Scheffé \\
\hline Between group & & & & & \\
$\quad$ Group & 14.178 & 2 & 7.089 & $0.254^{* * *}$ & $1<2,3$ \\
Error & $1,591.580$ & 57 & 27.922 & & \\
Within group & & & & & \\
Task type & 0.145 & 1 & 0.145 & 0.005 & \\
Task type $\times$ Group & 14.178 & 2 & 7.089 & 0.254 & \\
Error & $1,591.580$ & 57 & 27.922 & & \\
\hline
\end{tabular}

$1=1$ st grade $2=2$ nd grade 3 =3rd grade .

${ }^{* * *} p<.001$.

다음과 같다(Table 4, Figure 2).

학년과 과제 유형에 따른 철자 쓰기 능력에 차이가 있는지 알아 보기 위해 반복측정 이원분산분석을 실시한 결과는 Table 5 와 같 다. 철자 쓰기 과제 유형에 따른 학년 간 차이를 살펴본 결과 학년 간 $F_{(2,57)}=.254(p<.001)$ 로 나타났고, 사후분석 결과, 1 학년이 2,3 학년보다 철자 쓰기 정확률이 유의미하게 낮은 것으로 나타났다. 과제 유형 간에는 $F_{(1,57)}=.005$ ( $p>.05$ 로 유의미하지 않았다. 학년 과 과제 유형의 상호작용 효과는 $F_{(2,57)}=.254$ ( $\left.p>.05\right)$ 로 유의미하 지 않은 것으로 나타났다.

\section{학년(1, 2, 3학년)에 따른 언어학적 단위(단어, 문장)별 오류 유형 특성 비교}

학년에 따른 단어 수준 과제의 오류 유형

학년에 따라 단어 수준 과제의 오류를 백분율로 나타낸 기술 통 계 결과는 다음과 같다(Table 6, Figure 3).

초등 $1,2,3$ 학년 아동의 단어 수준의 오류 유형을 살펴본 결과, 표기 처리 오류, 형태 처리 오류, 음운 처리 오류, 무응답 순으로 높 게 나타났다. 단어 수준의 오류 유형을 세부적으로 살펴본 결과, 표 기 처리 오류는 전체 소리나는 대로, 동일한 소리, 일부 소리를 소리 
Table 6. Types of errors in word level by subgroup

\begin{tabular}{lcccc}
\hline Error & $\begin{array}{c}\text { 1st grade } \\
(\mathrm{N}=20)\end{array}$ & $\begin{array}{c}\text { 2nd grade } \\
(\mathrm{N}=20)\end{array}$ & $\begin{array}{c}\text { 3rd grade } \\
(\mathrm{N}=20)\end{array}$ & $\begin{array}{c}\text { Total } \\
(\mathrm{N}=60)\end{array}$ \\
\hline Phonological errors & $20.06(9.10)$ & $16.26(13.21)$ & $12.17(9.79)$ & $16.16(11.41)$ \\
Orthographic errors & $47.52(9.04)$ & $45.61(10.50)$ & $48.64(9.37)$ & $47.26(9.74)$ \\
Morphological errors & $31.01(4.87)$ & $38.11(9.86)$ & $39.18(12.88)$ & $36.10(10.24)$ \\
Non response & $0.01(0.02)$ & 0 & 0 & 0 \\
\hline
\end{tabular}

Values are presented as mean (SD).

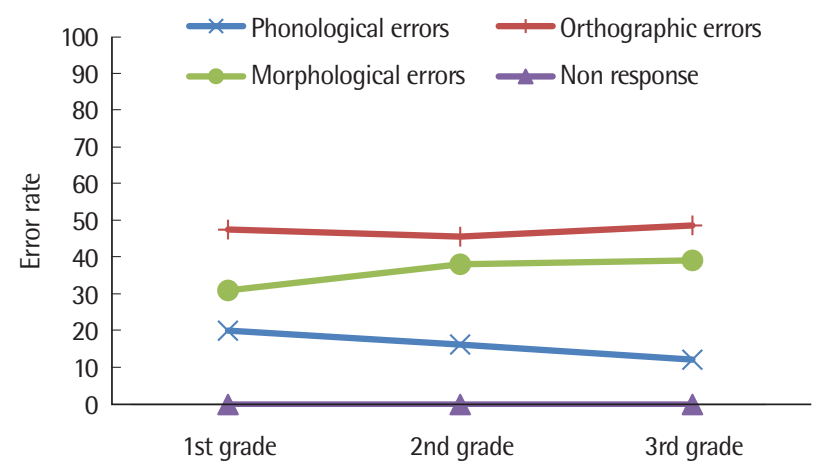

Figure 3. Types of errors in word level by subgroup.

나는 대로, 없는 소리 순으로 나타났고, 형태 처리 오류는 어간/어 미, 어근/접사, 다른 어미/접사, 동음이의어 순으로 나타났으며, 음 운 처리 오류는 무의미 단어로 대치, 의미 단어로 대치 순으로 높게 나타났다.

학년 별로 살펴보면, 1, 2, 3학년 모두 표기 처리 오류, 형태 처리 오류, 음운 처리 오류 순으로 높았고, 세부적으로 살펴보았을 때 표 기 처리 오류에서 전체 소리나는 대로, 동일한 소리, 일부 소리나는 대로, 없는 소리 순으로 높았으며 형태 처리 오류에서는 어간/어미, 어근/접사, 다른 어미/접사, 동음이의어, 음운 처리 오류는 무의미 단어로 대치, 의미 단어로 대치 순으로 높게 나타났다. 따라서 학년 별로 오류 유형을 세부적으로 살펴보았을 때 오류율의 차이는 있 었지만 오류 유형의 순서에는 차이가 없었다.

\section{학년에 따른 문장 수준 과제의 오류 유형}

학년에 따라 문장 수준 과제의 오류를 백분율로 나타낸 기술 통 계 결과는 다음과 같다(Table 7, Figure 4).

초등 $1,2,3$ 학년 아동의 문장 수준의 오류 유형을 살펴본 결과, 표 기 처리 오류, 형태 처리 오류, 음운 처리 오류, 무응답 순으로 높게 나타났다. 문장 수준의 오류 유형을 세부적으로 살펴본 결과, 표기 처리 오류는 전체 소리나는, 동일한 소리, 일부 소리를 소리나는 대 로, 없는 소리 순으로 나타났고, 형태 처리 오류는 어간/어미, 어근/
Table 7. Types of errors in sentence level by subgroup

\begin{tabular}{lcccc}
\hline Error & $\begin{array}{c}\text { 1st grade } \\
(\mathrm{N}=20)\end{array}$ & $\begin{array}{c}\text { 2nd grade } \\
(\mathrm{N}=20)\end{array}$ & $\begin{array}{c}\text { 3rd grade } \\
(\mathrm{N}=20)\end{array}$ & $\begin{array}{c}\text { Total } \\
(\mathrm{N}=60)\end{array}$ \\
\hline Phonological errors & $27.71(10.67)$ & $18.18(11.14)$ & $19.56(12.77)$ & $21.81(12.38)$ \\
Orthographic errors & $42.23(10.91)$ & $48.02(7.48)$ & $45.30(11.88)$ & $45.18(10.52)$ \\
Morphological errors & $29.27(7.21)$ & $33.16(9.88)$ & $35.13(12.27)$ & $32.52(10.12)$ \\
Non response & $0.77(1.40)$ & $0.62(1.18)$ & 0 & $0.46(0.88)$ \\
\hline
\end{tabular}

Values are presented as mean (SD).

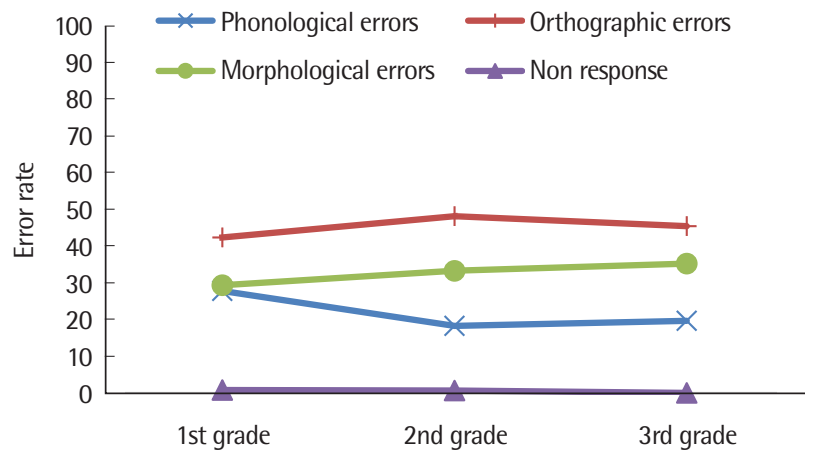

Figure 4. Types of errors in sentence level by subgroup.

접사, 다른 어미/접사, 동음이의어 순으로 나타났으며 음운 처리 오 류는 무의미 단어로 대치, 의미 단어로 대치 순으로 높게 나타났다.

학년 별로 살펴보면, 1, 2, 3학년 모두 표기 처리 오류, 형태 처리 오류, 음운 처리 오류 순으로 높았고, 세부적으로 살펴보았을 때 표 기 처리 오류에서 전체 소리나는 대로, 동일한 소리, 일부 소리나는 대로, 없는 소리 순으로 높았으며 형태 처리 오류에서는 어간/어미, 어근/접사, 다른 어미/접사, 동음이의어 순으로 $1,2,3$ 학년 모두 동 일하였다. 하지만 음운 처리 오류는 1,2 학년에서 무의미 단어로 대 치, 의미 단어로 대치 순으로 높게 나타났으나 3 학년에서는 의미 단 어로 대치, 무의미 단어로 대치 순으로 높았다. 따라서 학년 별로 오 류 유형을 세부적으로 살펴보았을 때 오류율의 차이는 있었지만 오류 유형의 순서는 유사하였다.

\section{논의 및 결론}

본 연구는 초등 저학년(1-3학년) 일반 아동의 언어학적 단위에 따른 철자 쓰기 능력과 오류 유형에 따른 철자 쓰기 특성을 알아보 고자하였다.

첫째, 학년과 언어학적 단위(단어, 문장 수준: 전체 어절)에 따른 철자 쓰기 정확률을 비교하였을 때 1학년보다 2, 3학년이, 2학년보 다 3학년의 철자 쓰기 정확률이 높은 것으로 나타났다. 학년이 높 
아짐에 따라 철자 쓰기 정확률이 증가하였다. 철자 쓰기 능력을 과 제 유형에 따라 살펴보았을 때, 문장 수준 과제에서 전체 어절 정확 률이 단어 수준 정확률에 비해 유의미하게 높은 것으로 나타났다. 그러나 학년과 과제 유형 간에 상호작용 효과는 없는 것으로 나타 났다. 선행 연구에서 초등 $1,2,3$ 학년을 대상으로 실시한 단어 수준 의 철자 검사를 실시한 결과, 일반 아동의 철자 정확률이 학년이 높 아질수록 평균 점수는 증가하고 표준 편차는 감소하는 경향을 보 인다고 하였다(Yang, 2014). 본 연구에서도 단어 수준 과제에서 학 년이 높아짐에 따라 정확률이 증가하였고, 표준 편차 역시 감소하 는 경향을 보였다. 이와 같이 초등 저학년 시기에 학년이 높아질수 록 철자 쓰기 능력이 단어 수준에서 점차 완성된다고 해석할 수 있 다. 초등 1-6학년을 대상으로 낱말과 문장 수준 과제에서 어절 및 자소 단위로 나누어 분석하였을 때 어절 단위에서는 1 학년에서 3 학년, 자소 단위에서는 1 학년에서 2 학년에 급격한 발달을 보인다고 하였다(Shin, Seol, Cho, Nam \& Pae, 2015). 이러한 결과는 본 연구 에서 살펴본 문장 수준 과제의 전체 어절 정확률과 동일한 결과였 다. 이는 전체 어절로 채점할 경우 목표 단어와 문법형태소가 결합 된 어절의 정확률이 높아진다는 점을 시사하며, 쓰기 중재 시 문맥 에 대한 활용과 형태 인식의 필요성을 뒷받침한다고 볼 수 있다. 따 라서 받아쓰기 시 의미적 단서를 제공하거나 형태 인식을 활용한 전략을 습득하도록 한다면 철자 쓰기의 정확률을 높일 수 있을 것 으로 사료된다.

학년과 언어학적 단위(단어, 문장 수준: 목표 단어)에 따른 철자 쓰기 정확률을 비교하였을 때, 1 학년이 2, 3학년에 비해 유의미하게 낮았다. 학년이 높아짐에 따라 철자 쓰기 정확률이 증가하였다. 과 제 유형 간에는 단어 수준과 문장 수준에서 유의미한 차이가 나타 나지 않았다. 그리고 학년과 과제 유형 간에 상호작용 효과가 없는 것으로 나타났다. 이는 초등 저학년에서 철자 쓰기 발달이 지속적 으로 활발하게 이루어지고 있지만 특히 1 학년에서 2 학년 사이의 철 자 쓰기 발달이 매우 중요하므로 이 시기에 이루어지는 발달과 어 떤 오류들이 나타나는지도 함께 고려하여야 하며 학년에 따른 수 준을 파악하여 단계 별 접근이 이루어져야 한다. 과제 유형 간에는 단어 수준과 문장 수준에서 유의미한 차이가 없었다. 이는 목표 단 어에 대한 정확률을 살피고자 할 때 단어 수준 과제와 문장 수준 과제 중 한 가지만 실시하여도 철자 쓰기 능력을 살펴보는데 큰 차 이가 없음을 시사한다. 즉, 단어 수준 과제만 실시하였을 경우 문장 수준에서 목표 단어의 정확률을 예측할 수 있고, 반대로 문장 수준 과제만 실시하였을 경우에도 문장 내 쓰여진 단어로도 정확률을 예측 가능하다고 할 수 있다. 따라서 이러한 결과들을 토대로 살펴 보았을 때, 초등 저학년의 특성을 고려한 평가나 중재가 이루어져
야함을 의미한다. 또한, 학년마다 철자 쓰기 능력이 차이가 있기 때 문에 이러한 차이의 근거가 될 수 있는 오류 유형에 대한 평가가 이 루어져야함을 뒷받침한다.

둘째, 학년과 언어학적 단위에 따른 철자 오류 유형을 분석한 결 과, 모든 학년에서 표기 처리 오류, 형태 처리 오류, 음운 처리 오류, 무응답 순으로 높게 나타났다. 학년이 증가하면서 음운 처리 오류 의 감소가 가장 크게 나타났고, 그 중에서도 무의미 단어로 대치하 는 오류들이 크게 줄어들었다. 그리고 3학년이 되어서도 여전히 표 기 처리 오류와 형태 처리 오류에 어려움이 있는 것으로 나타났다. 이는 초등 1-2학년에 음운 처리 오류가 주된 오류로 나타난다는 선 행연구를 지지하는 바이며(Berninger, Abbott, Nagy \& Carlisle, 2010), 초등 저학년 시기의 쓰기에는 음운적 지식이 많이 관여되지 만 점차 학년이 올라가면서 형태 인식으로 비율이 변화한다고 하였 다(Apel, Wilson-Fowler, Brimo, \& Perrin, 2012). 또한, 초등 저학년 이 되어서도 마지막 단계인 형태 전략의 사용에 어려움이 있다고 한 선행 연구(Han \& Jung, 2018)와도 일치하였다. 음운 처리 단계 에서 패턴 처리 단계와 형태 처리 단계로 접어들면서 자소-음소 불 일치형에 대한 수행률이 높아지기 시작한다. 따라서 학년이 높아질 수록 음운 규칙에 대한 쓰기 정확률이 증가한다는 연구들을 뒷받 침할 수 있다(Kim, 2016; Yang, 2014). Henderson (1990)이 초등 저 학년 아동들이 철자 쓰기를 할 때 주로 음운 전략을 사용하며 형태 전략에는 어려움이 있다는 것과 같은 맥락으로 볼 수 있다. 따라서 철자 쓰기 발달 단계로 살펴볼 때, 초등 저학년 시기에는 글자 또는 낱말의 위치에 따라 다르게 철자 쓰기가 이루어진다는 원리와 모 든 단어가 자소-음소 대응하여 철자 쓰기가 이루어지지 않는다는 것을 인식하게 되는 표기 처리 단계와 의미를 지닌 부분은 소리가 바뀌더라도 철자는 변하지 않는다는 것을 인식하여 적용하는 형태 처리 단계에 머물러 있는 것으로 생각할 수 있다. 또한, 형태 처리 단 계에 머물러있다는 결과를 바탕으로 학년이 높아질수록 형태 인식 을 강조한 철자 쓰기가 필요하다는 것을 의미한다.

언어학적 단위에 따라 오류 유형을 살펴보았을 때, 단어 수준 과 제와 문장 수준 과제에서 표기 처리 오류, 형태 처리 오류, 음운 처 리 오류, 무응답 순으로 높아 오류 특성이 유사하였다. 단어 수준 과제의 오류율을 세부적으로 살펴보면 표기 처리 오류는 전체 소 리나는 대로, 동일한 소리, 일부 소리를 소리나는 대로, 없는 소리 순으로 나타났고, 형태 처리 오류는 어간/어미 및 어근/접사, 다른 어미 및 접사 순으로 나타났으며, 동음이의어는 나타나지 않았다. 음운 처리 오류는 무의미 단어로 대치, 의미 단어로 대치 순으로 나 타났다. 이는 학년별로 살펴보았을 때도 동일한 순서로 높게 나타 났다. 문장 수준 과제에서 세부적으로 오류를 살펴보면 표기 처리 
오류는 전체 소리나는 대로, 동일한 소리, 일부 소리를 소리나는 대 로, 없는 소리 순으로 나타났고, 형태 처리 오류는 어간/어미 및 어 근/접사, 다른 어미 및 접사, 동음이의어 순으로 나타났으며 음운 처 리 오류는 무의미 단어로 대치, 의미 단어로 대치 순으로 나타났다. 학년 별로 살펴보았을 때 $1,2,3$ 학년 모두 표기 처리 오류, 형태 처리 오류, 음운 처리 오류 순을 동일하였고, 세부적으로 살펴보았을 때 에도 표기 처리 오류는 전체 소리나는 대로, 동일한 소리, 일부 소리 를 소리나는 대로, 없는 소리 순으로 나타났고, 형태 처리 오류는 어 간/어미 및 어근/접사, 다른 어미 및 접사, 동음이의어 순으로 높게 나타나 동일한 오류 패턴을 보였다. 하지만 음운 처리 오류는 1,2 학 년은 무의미 단어로 대치, 의미 단어로 대치한 순으로 나타났으나 3 학년은 의미단어로 대치, 무의미 단어로 대치 순으로 높게 나타났다.

이는 과제 유형이 다르더라도 비슷한 오류 패턴을 보인다는 것을 의미한다. 자소-음소 불일치형의 경우 자소-음소 일치형보다 표기 처리 오류와 형태 처리 오류가 나타날 가능성이 높기 때문에 나타 난 결과라고 볼 수 있다. 오류 유형을 분석할 때 표기 처리 오류와 형태 처리 오류가 중복으로 나타난 경우가 많았다. 예를 들어 '쌓지' 를 '쌓치', '굽히지'를 ‘굽피지'와 같은 오류를 보였을 경우 표기 처리 오류의 일부 소리나는 대로, 형태 처리 오류의 어간/어미, 어근/접 사에 해당되었다. 이는 초등 저학년 시기에 형태 인식을 바탕으로 하여 동사가 다양한 형태로 활용될 경우 어려움을 보인다는 의미 로 해석할 수 있겠다. 단어 수준, 문장 수준 모두 학년이 높아짐에 따라 오류율이 감소하였다. 두 가지 과제에서 모두 음운 처리 오류 에서 가장 큰 감소를 보였다. 특히 1 학년에서 2 학년이 되면서 크게 감소하는 경향이 나타났고, 이는 소리에 대응하는 철자 능력이 발 달한다는 것으로 해석할 수 있으며 이 때 자소-음소 일치형에 대한 수행이 크게 증가한 것으로 예측할 수 있다. 따라서 초등 저학년 시 기에 자소-음소 일치형 발달은 완성이 되고 있으나자소-음소 불일 치형 발달은 여전히 이루어지고 있으며 특히, 동사가 활용되는 경 우에 어려움이 크다는 것을 알 수 있었다. 이를 중재에 적용한다면, 형태 지식을 활용할 수 있도록 기본형을 제공하고 다양한 어미와 접사로 단어가 활용되는 원리를 강조하여 중재한다면 표기 처리 오 류와형태처리 오류 모두 감소시킬 수 있을 것으로 사료된다.

본 연구에서는 초등 저학년(1,2,3학년) 아동의 언어학적 단위에 따른 철자 쓰기 특성을 살펴보았다. 본 연구의 실험 도구는 1-4학년 의 교과서와 실제 학교 현장에서 사용되고 있는 1-3학년 받아쓰기 급수표를 참조하여 제작하였지만 차후, 실생활에 친숙도를 고려한 쓰기 연구도 의미가 있을 것이다. 또한, 학령전기, 초등 고학년 $(4,5$, 6학년)을 대상으로 철자 쓰기 발달 특성을 함께 살펴보는 후속연 구도 필요할 것이다.

\section{REFERENCES}

Aan, N. R., \& Lee, K. J. (2019). Effects of playing with letters for making words on decoding ability of students with intellectual disabilities. Journal of Elementary Education, 35(1), 25-42.

Apel, K., \& Masterson, J. J. (2001). Theory-guided spelling assessment and intervention. Language, Speech, and Hearing Services in Schools, 32(3), 182195.

Apel, K., Wilson-Fowler, E. B., Brimo, D., \& Perrin, N. A. (2012). Metalinguistic contributions to reading and spelling in second and third grade students. Reading and Writing, 25, 1283-1305.

Bae, H. S. (2015). Analysis on writing development of school-aged children from multicultural families. Multicultural Education Studies, 8(4), 161-179.

Bae, H. S. (2016). Analysis on writing development of school-aged children: focusing on formal elements. Korean Journal of Linguistics, 41(1), 21-40.

Baek, J. H. (2009). A study on teaching writing through pictures (master's thesis). Ewha Woman University, Seoul, Korea.

Berninger, V. W., Abbott, R. D., Jones, J., Wolf, B. J., Gould, L., Anderson-Youngstrom, M., \& Apel, K. (2006). Early development of language by hand: composing, reading, listening, and speaking connections; three letter-writing modes, and fast mapping in spelling. Developmental Neuropsychology, 29(1), 61-92.

Beringer, V. W., Abbott, R. D., Nagy, W., \& Carlisle, J. (2010). Growth in phonological, orthographic, and morphological awareness in grade 1 to 6. Journal of Psycholinguistic Research, 39(2), 141-163.

Berninger, V. W., Cartwright, A. C., Yates, C. M., Swanson, H. L., \& Abbott, R. D.(1994). Developmental skills related to writing and reading acquisition in the intermediate grades. Reading and Writing, 6(2), 161-196.

Byun, Y. J. (2005). Correlations among dictation, vocabulary and phrase abilities of young school children (Master's thesis). Myongji University, Seoul, Korea.

Han, H. J., \& Kim, M. (2018). Correlation among morphological awareness, reading fluency and spelling for school-aged children with language-learning disabilities in third to fourth grades. Communication Sciences \& Disorders, 23(2), 347-359.

Han, S. I., \& Jung, K. H. (2018). Spelling characteristics of early grade elementary school children with language learning disabilities. Communication Sciences \& Disorders, 23(2), 313-326.

Henderson, E. H. (1990). Teaching spelling (2nd ed). Boston, MA: Houghton Mifflin. 
Henderson, E. H., \& Templeton, S. (1986). A developmental perspective of formal spelling instruction through alphabet, pattern, and meaning. The Elementary School Journal, 86(3), 305-316.

Jung, K. H. (2019). Developmental characteristics of spelling ability of kindergarten to 3rd grade children. Communication Sciences \& Disorders, 24(1), 19-30.

Katusic, S. K., Colligan, R. C., Weaver, A. L., \& Barbaresi, W. J. (2009). The forgotten learning disability: epidemiology of written-language disorder in a population-based birth cohort (1976-1982), Rochester, Minnesota. Pediatrics, 123(5), 1306-1313.

Kim, A. H. (2016). Comparison of spelling between students with and without writing disabilities: spelling achievement differences and predictors for spelling. Journal of Learner-Centered Curriculum and Instruction, 16(1), 697-722.

Kim, A. H., Choi, H. N., \& Kim, J. H. (2010). Spelling skills of students with or without spelling difficulties in Korea: focusing on spelling accuracy and error patterns. Korean Journal of Special Education, 45(1), 203-223.

Kim, B. B., Lee, A. J., \& Yang, M. H. (2018). The influence of letter knowledge and phonological processing on the word reading and spelling of young elementary students with dyslexia. The Korean Journal of Learning Disabilities, 15(2), 67-85.

Kim, B. B., \& Yang, M. H. (2015). Articulatory information for spelling strategies. Communication Sciences \& Disorders, 20(3), 400-412.

Kim, K. H. (2003). Vocabularies for different levels of Korean education. Seoul: Pagijung.

Kim, Y. S. G., Gatlin, B., Al Otaiba, S., \& Wanzek, J. (2018). Theorization and an empirical investigation of the component-based and developmental text writing fluency construct. Journal of Learning Disabilities, 51(4), 320335.

Kim, Y. T., Hong, G. H., Kim, K. H., Jang, H. S., \& Lee, J. Y. (2009). Receptive \& expressive vocabulary test (REVT). Seoul: Seoul Community Rehabilitation Center.

Ko, U. (2007). Analysis on factors that influence the writing skill development of preschoolers. Journal of Speech-Language \& Hearing Disorders, 16(2), 109-129.

Koutsoftas, A. D. (2016). Writing process products in intermediate-grade children with and without language-based learning disabilities. Journal of Speech, Language, and Hearing Research, 59(6), 1471-1483.

Lee, K. W., Lee, G. B., \& Kim, M. H. (2018). The writing expression characteristics on the diary in elementary school. Journal of the Elementary Edu- cation Society, 29, 19-32.

McNeill, B. C., Wolter, J., \& Gillon, G. T. (2017). A Comparison of the metalinguistic performance and spelling development of children with inconsistent speech sound disorder and their age-matched and reading-matched peers. American Journal of Speech-Language Pathology, 26(2), 456-468.

Moats, L. C. (1994). The missing foundation in teacher education: knowledge of the structure of spoken and written language. Annals of Dyslexia, 44(1), 81-102.

Pae, S., Kim, M., Yoon, H. J., \& Jahng. S. (2015). Korean language based reading assessment (KOLRA). Seoul: Hakjisa.

Park, H. O., \& Chung, Y. S. (2008). A study on dictation errors and dictation error characteristics of the elementary student. Journal of Special Education: Theory and Practice, 9(4), 367-395.

Park, H. W. (2014). Korean Comprehensive Test of Nonverbal Intelligence-2 (K-CTONI-2). Seoul: Mindpress.

Seo, K. H. (2006). Analysis of types of orthographical errors in fourth and fifth graders in elementary school (Master's thesis). Daegu University, Gyeongbuk, Korea.

Shin, G. Y., Seol, A. Y., Cho, H. S., Nam, K. C., \& Pae, S. Y. (2015). Korean spelling development and linguistic patterns. Journal of Speech \& Hearing Disorders, 24(2), 61-72.

Sumner, E., Connelly, V., \& Barnett, A. L. (2016). The influence of spelling ability on vocabulary choices when writing for children with dyslexia. Journal of Learning Disabilities, 49(3), 293-304.

Tops, W., Callens, M., Bijn, E., \& Brysbaert, M. (2012). Spelling in adolescents with dyslexia: errors and modes of assessment. Journal of Learning Disabilities, 47(4), 295-306.

Van Kleeck, A. (1994). Potential cultural bias in training parents as conversational partners with their children who have delays in language development. American Journal of Speech-Language Pathology, 3(1), 67-78.

Vellutino, F., Fletcher, J., Snowling, M., \& Scalon, D. (2004). Specific reading disability (dyslexia): what have we learned in the past four decades? Journal of Child Psychology and Psychiatry, 45(1), 2-40.

Yang, M. (2009). Spelling development of kindergarten students: a one year longitudinal study. Korean Journal of Communication \& Disorders, 14(1), 14-33.

Yang, M. (2014). Children's spelling of phonological and morphological features in primary grades. Communication Sciences \& Disorders, 19(1), 120131.

Yang, M. H., Kim, B. B., \& Ra, J. M. (2017). Predicting word reading and spell- 


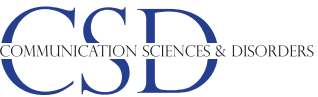

ing in first graders with dyslexia. Communication Sciences \& Disorders, 22(4), 690-704.

Ye, J. W., Kim, W. S., \& Rhee, K. Y. (2017). The analysis study on students with mild intellectual disability's narrative writing abilities. Journal of Special
초등 저학년 아동의 철자 쓰기 발달 특성 - 고은이 외

Education \& Rehabilitation Science, 56(2), 219-236.

Yoo, S. A. (2008). Longitudinal analysis of development in writing stories by elementary school lower graders. Journal of Cheong Ram Korean Language Education, 67, 265-293. 
Appendix 1. Spelling test (word/sentence)

\begin{tabular}{|c|c|c|c|}
\hline 음운규칙 & 단어 & 문장 & 근거 \\
\hline \multirow[t]{4}{*}{ - (4) } & 느낌 & 느낌을 이야기해요 & 국어 2-2 (가) \\
\hline & 병원 & 병원에 가야지 & 국어 2-1 (나), 1학년 급수표, 2학년 급수표 \\
\hline & 규칙 & 규칙이 없다면 어떨까요 & 수학 1-2 \\
\hline & 예절 & 언어 예절을 지키며 말했다 & 국어 3-2 (나) \\
\hline \multirow[t]{4}{*}{ 종성규칙(4) } & 까닭 & 까닭 없이 준비물을 빌려주지 않았다 & 국어 3-2 (나) \\
\hline & 마음껏 & 마음껏 뛰어 놀 수도 있다 & 사회 3-1 \\
\hline & 부억 & 부억을 나누어 사용했어요 & 사회 3-2 \\
\hline & 숲 & 숲 가운데에 찻길이 생긴 거예요 & 국어 2-1 (가) \\
\hline \multirow[t]{4}{*}{ 연음화(4) } & 목욕 & 목욕부터 하면 좋겠어 & 국어 1-1 (나), 1학년 급수표 \\
\hline & 묶음 & 몇 묶음인지 세어 봅시다 & 수학 2-1 \\
\hline & 공기놀이 & 학교에서 친구들과 공기놀이를 했어요 & 국어 2-1 (가), 2학년 받아쓰기 급수표 \\
\hline & 단원 & 단원을 학습하면서 해결해 봐요 & 과학 4-1 \\
\hline \multirow[t]{4}{*}{ 경음화(4) } & 가볍게 & 짐을 가볍게 해요 & 국어 3-1 (나) \\
\hline & 목소리 & 목소리가 우렁차구나 & 국어 1-1 (나) \\
\hline & 좁다 & 강폭이 좁다 & 실험관찰 3-2 \\
\hline & 약자 & 약자가 있다 & 국어 4-1 (가) \\
\hline \multirow[t]{4}{*}{ 기식음화(4) } & 어떻게 & 자신이 이 아이라면 어떻게 할까요 & 국어 3-2 (가) \\
\hline & 좋다 & 어떤 점이 좋다고 하셨나요 & 국어 2-2 (가) \\
\hline & 굽히지 & 뜻을 굽히지 않았어요 & 국어활동 4-2 \\
\hline & 쌓지 & 계단에는 물건을 쌓지 말라고 하셨어 & 국어 2-2 (가) \\
\hline \multirow[t]{4}{*}{ 구개음화(4) } & 굳이 & 오늘 굳이 밥을 먹어야 할까 & 사회 3-2 \\
\hline & 굳히면 & 그릇에 담아 굳히면 빨랫비누가 완성되지요 & 국어활동 3-2 \\
\hline & 가을걷이 & 가을걷이하는 사람들을 살펴봅시다 & 국어 4-1 (나) \\
\hline & 갇혀 & 갇혀 있었다고요 & 국어 3-2 (나) \\
\hline
\end{tabular}

Appendix 2. Type of spelling ability error

\begin{tabular}{|c|c|c|}
\hline 오류 유형 & 정의 & 예시 \\
\hline 음운 처리 오류(phonological errors) & $\begin{array}{l}\text { 자소와 음소를 대응하지 못하여 나타나는 오류로 무의미 단어로 대치, 의미 단어로 대치 } \\
\text { 하는 경우가 있음 }\end{array}$ & $\begin{array}{l}\text { 규칙 } \rightarrow \text { 구칙 } \\
\text { 좁다 } \rightarrow \text { 잡다 }\end{array}$ \\
\hline 표기 처리 오류(orthographic errors) & $\begin{array}{l}\text { 모든 단어가 자소-음소 대응하여 철자되지 않는다는 것을 인식하지 못하여 나타나는 오 } \\
\text { 류로 동일한 소리로 적거나 단어의 전체/일부 소리를 소리대로 표기하는 경우, 한글에 } \\
\text { 없는 글자로 표기하는 경우가 있음 }\end{array}$ & $\begin{array}{l}\text { 까닭 } \rightarrow \text { 까닥 } \\
\text { 목욕 } \rightarrow \text { 모곡 } \\
\text { 공기놀이 } \rightarrow \text { 공기놀리 }\end{array}$ \\
\hline 형태 처리 오류(Morphological errors) & $\begin{array}{l}\text { 의미를 지닌 부분은 소리가 바뀌더라도 철자는 변하지 않는다는 것을 인식하지 못하여 } \\
\text { 나타나는 오류로 발음에 영향을 받아 어간/어미 또는 어근/접사가 변형된 단어로 표기 } \\
\text { 하는 경우, 어미나 접사를 삽입하거나 다른 어미나 접사로 대치한 경우, 소리가 같은 동 } \\
\text { 음이의어로 표기하는 경우가 있음 }\end{array}$ & $\begin{array}{l}\text { 좋다 } \rightarrow \text { 좋타 } \\
\text { 쌓지 } \rightarrow \text { 쌓는 }\end{array}$ \\
\hline
\end{tabular}




\section{국문초록}

\section{초등 저학년 아동의 언어학적 단위(단어/문장)에 따른 철자 쓰기 발달 특성}

\section{고은이 ${ }^{1} \cdot$ 신명선 ${ }^{2} \cdot$ 김미배 ${ }^{3}$}

${ }^{1}$ 아이공감 정신건강의학과의원 언어치료실, ${ }^{2 ㅂ ㅜ ㅅ ㅏ ㄴ ㄱ ㅏ ㅌ ㅗ ㄹ ㄹ ㅣ ㄱ ㄷ ㅐ ㅎ ㅏ ㄱ ㄱ ㅛ ~ ㅇ ㅓ ㄴ ㅇ ㅓ ㅊ ㅓ ㅇ ㄱ ㅏ ㄱ ㅊ ㅣ ㄹ ㅛ ㅎ ㅏ ㄱ ㄱ ㅘ, ~}{ }^{2}$ 다온언어학습연구소

배경 및 목적: 초등 저학년(1-3학년) 일반 아동을 대상으로 학년별 단어와 문장 수준의 받아쓰기 과제를 통해 철자 쓰기 정확률 및 오 류 유형에 따른 철자 쓰기 특성을 살펴보고자 하였다. 방법: 초등 1-3학년(각 학년별 20명) 일반 아동 총 60 명을 대상으로 하였다. 철자 쓰기 검사 도구는 2017년, 2018년 개정 교과서와 실제 학교 현장에서 사용되고 있는 1-3학년 받아쓰기 급수표를 기반으로 단어 수준 과 제에서 실시한 낱말을 문장 수준에 포함되도록 구성하였다. 결과: 첫째, 단어 수준 과제 정확률이 문장 수준 과제의 전체 어절 정확률 보다 유의하게 낮았고, 단어 수준 과제와 문장 수준 과제의 목표 낱말 정확률은 유의미한 차이가 나타나지 않았다. 둘째, 모든 학년에서 표기 처리 오류, 형태 처리 오류, 음운 처리 오류 순으로 높았고, 단어 수준, 문장 수준 모두 표기 처리 오류, 형태 처리 오류, 음운 처리 오 류 순으로 높게 나타나 오류 특성이 유사하였다. 논의 및 결론: 철자 쓰기 발달이 초등 저학년 시기에 활발하게 이루어는 중요한 능력임 을 확인하였다. 따라서 임상현장에서 철자 쓰기에 어려움이 있는 아동들의 평가 및 중재 시에 학년별 쓰기 발달 특성을 고려하여 효율 적인 쓰기 지도가 이루어지기를 기대한다.

핵심어: 학령기, 초등 저학년, 쓰기 발달, 철자 쓰기, 철자 오류 유형

본 논문은 2020년 1저자의 석사학위 논문을 수정 및 보완하였음.

\section{참고문헌}

고은(2007). 취학 전 아동의 쓰기발달에 영향을 미치는 요인분석. 언어치료연구, 16(2), 109-129.

김광해(2003). 등급별 국어교육용 어휘. 서울: 박이정.

김보배, 양민화(2015). 일반 아동과 철자 부진 아동의 철자 전략 비교: 음소의 조음 정보 중심으로. Communication Sciences \& Disorders, 20(3), 400-412.

김보배, 이애진, 양민화(2018). 저학년 난독증 아동의 단어인지와 철자 능력에 대한 자모지식과 음운처리 능력의 영향력 연구. 학습장애연구, 15(2), 67-85.

김애화, 최한나, 김주현(2010). 초등학교 철자부진학생과 일반학생의 철자 특성 비교 연구. 특수교육학연구, 45(1), 203-223.

김애화(2016). 일반 초등학생과의 비교를 통한 쓰기장애 초등학생의 철자 특성 연구: 철자 성취도 차이 및 철자 성취도에 대한 예측 변인 연구. 학습장

애연구, 16(1), 697-722.

김영태, 홍경훈, 김경희, 장혜성, 이주연(2009). 수용-표현어휘력검사(Receptive \& Expressive Vocabulary test: REVT). 서울장애인종합복지관. 박혜옥, 정용석(2008). 초등학생의 받아쓰기 발달과 오류 특징에 관한 연구. 특수교육저널: 이론과 실천,9(4),367-395.

박혜원(2014). 한국 비언어 지능검사(K-CTONI-2). 서울: 마인드프레스.

배소영, 김미배, 윤효진, 장승민(2015). 한국어읽기검사(Korean Language-based Reading Assessment; KOLRA). 서울: 학지사.

배희숙(2015). 초등학교 저학년 다문화가정 아동의 쓰기 발달 특성 분석. 다문화교육연구, 8(4), 161-179.

배희숙(2016). 학령기 아동의 쓰기 발달 분석: 형식적 요소를 중심으로. 한국언어학회, 41(1),21-40.

백주현(2009). 사진을 활용한 쓰기 교수-학습 방안. 이화여자대학교 교육대학원 석사학위논문.

변윤자(2005). 초기 학령기 아동의 받아쓰기 능력과 어휘 및 구문능력과의 상관관계. 명지대학교 사회교육대학원 석사학위 논문. 서경희(2006). 초등학생 4-5학년 학생들의 받아쓰기에 나타난 맞춤법 오류유형 분석. 대구대학교 재활과학대학원 석사학위논문. 신가영, 설아영, 조혜숙, 남기춘, 배소영(2015). 초등학생의 철자 발달과 오류 패턴 분석. 언어치료연구, 24(2), 61-72. 
안나리, 이기정(2019). 음운인식훈련에 근거한 글자 만들기 놀이가 지적장애 학생의 해독능력에 미치는 영향. 초등교육연구논총, 52(1), 25-42. 양민화(2009). 유치원 아동의 철자발달 단기종단연구. 언어청각장애연구, 14(1), 14-33.

양민화(2014). 음운론적 유형과 형태론적 유형의 초기 철자 발달. Communication Sciences \& Disorders, 19(1), 120-131.

양민화, 김보배, 나종민(2017). 초등학교 1학년 난독증 아동의 단어 읽기 및 철자능력 예측지표 연구. Communication Sciences \& Disorders, 22(4), 690-704.

예지원, 김화수, 이근용(2017). 경도지적장애 학생의 이야기 쓰기 분석. 특수교육재활과학연구, 56(2), 219-236.

유승아(2008). 초등 저학년의 이야기글 쓰기 발달에 대한 종단 분석. 청람어문교육, 67, 265-293.

이경화, 이근복, 김민희(2018). 초등학생 일기에 나타난 쓰기 표현 특성 연구. 초등교과교육연구, 29, 19-32.

정경희(2019). 유치원에서 초등 3학년 아동의 철자쓰기 발달 특성. Communication Sciences \& Disorders, 24(1), 19-30.

한송이, 정경희(2018). 초등 저학년 언어학습장애 아동의 철자쓰기 특성. Communication Sciences \& Disorders, 23(2), 313-326.

한효정, 김미배(2018). 초등 3-4학년 언어학습장애 아동의 형태소인식능력과 읽기유창성, 철자쓰기 간의 상관관계. Communication Sciences \& Disorders, 23(2), 347-359.

\section{ORCID}

고은이(제1저자, 언어재활사 https://orcid.org/0000-0002-8159-7886); 신명선(교신저자, 교수 https://orcid.org/0000-0002-4164-4991); 김미배(공동저자, 소장 https://orcid.org/0000-0001-9781-2520) 